\title{
Prevalence of sexual and physical abuse in patients with obstructed defecation: impact on biofeedback treatment
}

\author{
L. I. Solé, M. C. Bolino, M. Lueso, L. Caro, C. Cerisoli, N. Castiglia' and G. Bassotti²
}

Diagnostic and Therapeutic Gastroenterology Practice (GEDYT). 'Methodology Institute. Buenos Aires, Argentina. ${ }^{2}$ Gastroenterology and Hepatology Section. Department of Clinical \& Experimental Medicine. University of Perugia. Italy

\begin{abstract}
Background: obstructed defecation is one of the most common subtypes of constipation, and it is frequently responsive to biofeedback treatment.

Aims: since a history of sexual and physical abuse may be present in patients with obstructed defecation, we assessed the incidence of abuse history in patients with obstructed defecation referred to a general gastroenterology practice, and whether such a history may lead to a different outcome of biofeedback training in these patients.

Patients and methods: one hundred and twenty-one patients (17 men, 104 women, age $53 \pm 15$ years) with obstructed defecation were studied by retrospective chart review. Their history of sexual, physical and psychological abuse was obtained by a standard interview, and biofeedback training was carried out by means of a three-balloon technique.

Results: a history of sexual/physical or psychological abuse was present in $12.4 \%$ patients. Biofeedback training yielded a successful improvement of obstructed defecation in 93\% patients without abuse and in $100 \%$ of patients with abuse; this difference was not statistically different $(p=0.53)$.

Conclusions: the prevalence of sexual/physical or psychological abuse in a population of patients with obstructed defecation referred to a general gastroenterology practice is relatively low; such a history seems not to affect the outcome of biofeedback training in these patients.
\end{abstract}

Key words: Abuse. Biofeedback. Constipation. Obstructed defecation.

Solé LI, Bolino MC, Lueso M, Caro L, Cerisoli C, Pastiglia N, G. Bassotti. Prevalence of sexual and physical abuse in patients with obstructed defecation: impact on biofeedback treatment. Rev Esp Enferm Dig 2009; 101: 464-467.

Received: 03-02-09.

Accepted: 26-03-09.

Correspondence: Gabrio Bassotti. Clinica di Gastroenterologia ed Epatologia. Ospedale Santa Maria della Misericordia. Piazzale Menghini, 1. 06156 San Sisto (Perugia), Italy.e-mail: gabassot@tin.it

\section{INTRODUCTION}

Chronic constipation is a frequent complaint in clinical practice, and affects 3 to $30 \%$ of the general population in Western countries, particularly women (1). However, recent studies have shown that similar figures are also present in other countries, such as Latin America (2).

The pathophysiological basis of chronic idiopathic constipation may basically be reconducted to two main subtypes, slow-transit constipation (STC) and constipation due to obstructed defecation (OD) (3). The latter, after excluding anatomical or mechanical causes, may be often due to paradoxical contraction or failure to relax of the pelvic floor muscles during attempts to defecate, which impedes the outflow of feces $(4,5)$.

The prevalence of OD in different series varies between 25 and $70 \%(6,7)$. This probably reflects different population samples, with a prevalence of $7 \%$ in the general population (8). In many of these patients biofeedback treatment is very effective $(9,10)$.

Even though behavioral or psychological disturbances are frequently encountered in OD, it is still controversial whether these abnormalities are the cause or the consequence of this often disabling symptom (11).

Physical and/or psychical abuse are described with relative frequency in some functional gastrointestinal disorders, particularly in patients with irritable bowel syndrome (IBS) $(12,13)$; less data are available for constipated, non-IBS patients. Two recent studies reported that more than $32 \%$ of patients with OD had a history of physical and/or psychical abuse $(14,15)$. However, no data on the treatment of such patients are available.

The purpose of this study was: a) to establish the prevalence of sexual/physical or psychological abuse in a general gastroenterology practice of a Latin American population; and b) to assess whether patients with OD and a history of abuse respond differently to biofeedback treatment when compared to those without such a history of abuse. 


\section{PATIENTS}

We retrospectively reviewed the charts of all patients of a general gastroenterology practice - the Diagnostic and Therapeutic Gastrointestinal practice, GastroEnterología Diagnóstica y Terapéutica (GEDYT) - evaluated for OD that underwent biofeedback training during the period January 2004-January 2006. To be classified as OD the patients had: a) to fulfill Rome II criteria for constipation (16), i.e. two or more of six symptoms present for at least 12 weeks of the preceding 12 months: straining, lumpy or hard stools, sensation of incomplete evacuation, sensation of anorectal obstruction/blockage, or manual maneuvers to facilitate defecation on more than one fourth of bowel movements, or less than three evacuations per week; and b) paradoxical contraction or failure to relax pelvic floor muscles during attempts to defecate, as shown by anorectal manometry and defecography. It is worth noting that according to these criteria patients also met the recently published Rome III criteria for functional defecation disorder (17). Secondary causes of constipation were excluded by clinical and drug history taking, physical examination, blood chemistry, and colonoscopy or barium enema.

\section{METHODS}

\section{Diagnostic criteria of sexual, physical, and psychological abuse}

All patients were evaluated for sexual and physical abuse according to previously described criteria by means of a standard, previously validated questionnaire (18). This was done in a trustful clinical setting that ensured confidentiality and the patients' right not to disclose such information if unable or unwilling.

\section{Sexual abuse criteria}

Sexual abuse was defined as any of three types of sexual experiences: those involving attempts; those involving forced sexual touching with hand, mouth, or objects; and lastly, those in which vaginal or anal intercourse (rape) occurred $(19,20)$. Briefly, the questionnaire included the paraphrased items below. When you did not want it, has anyone ever: threatened to have sex with you, touched the sex organs of your body, made you touch the sex organs of their body, forced you to have sex, or have you had any other unwanted sexual experience?

\section{Physical abuse criteria}

Using the same interview for sexual abuse, we also included questions concerning physical abuse. We counted physical abuse only when it occurred as an event outside the sexual abuse incident. Thus, physical abuse in this study was counted only if the incident did not involve sexual abuse. Physical abuse was divided into two categories: beaten, hit, or kicked, and life threat $(19,20)$, and was evaluated by a multiple-choice answer given to the following question: when you were a child or nowadays, have you ever been beaten, hit or kicked by someone older than you or by other adult, respectively?: never; sometimes; occasionally; frequently. We considered physical abuse when "frequently" was answered, or when a brutal attack required medical aid or resulted in squeals.

\section{Psychological abuse criteria}

Psychological abuse was considered to be present when at least one affirmative response was given to the following questions: have you ever felt that someone in your family or at work made you feel that you had no value on several occasions? Have you ever been accused unjustifiably by a member of your family or at work on several occasions? Have you ever been asked too much of you by a member of your family or at work on several occasions? Have you ever been forced to attend family conflicts or difficult situations without being involved by a member of your family or at work on several occasions? For both sexual and physical abuse, yes/no responses were obtained.

\section{Biofeedback technique}

Biofeedback training (six weekly sessions of $30 \mathrm{~min}$ utes' duration) was carried out by means of a three-balloon manometric system (21). Biofeedback treatment involved measuring internal anal sphincter (IAS) relaxation and external anal sphincter (EAS) contraction by recording pressure changes in two intra-anal balloons, and using a third balloon for rectal distension. By gradually and progressively inflating the balloons located at the IAS and EAS levels, while simultaneously asking the patient to bear down, allowed the investigator and the patient to visualize on a computer screen the effects of simulated defecation. If during this maneuver a paradoxical contraction (i.e., increased pressure instead of relaxation during straining) of the sphincter was observed, the patient was instructed to relax in order to obtain a tracing similar to that of a normal subject, also displayed on the screen. Constant visual (by recording) and verbal reinforcements were given to patients by the therapist when correct responses were made, and the patients were encouraged to try harder or to modify their efforts in order to produce normal tracings (i.e., avoiding paradoxical contraction of the sphincter).

Patients were considered to have a successful biofeedback treatment if at the end of the training session they 
were able to normalize paradoxical contraction at manometry, to have at least two bowel movements per week without (or with sporadic, i.e. once or less per week) use of laxatives, and to refrain from the use of digital maneuvers to help defecation.

\section{Ethical considerations}

Since this was a retrospective study, no study-driven clinical intervention was performed; therefore only a simplified Institutional Review Board approval for retrospective studies was necessary.

\section{Statistical analysis}

Pre- and post-treatment data were compared by means of Fisher's exact test. $\mathrm{p}$ values $<0.05$ were chosen for rejection of the null hypothesis.

\section{RESULTS}

Chart review showed that $121 / 131$ (92\%) patients (17 men, 104 women, age $53 \pm 15$ years) were eligible for the study. The ten patients excluded were so for incomplete data (5 patients), and inability to fulfill the entry criteria (5 patients).

A history of abuse was found in 15/121 (12.4\%) patients (5 sexual; 10 physical or psychological). Once OD was diagnosed, all patients were treated with high-fiber diet and/or laxatives, and this regimen did not resolve the symptoms in 70 patients. These latter subjects were referred for biofeedback training.

Biofeedback treatment was thus carried out in 60 patients without a history of abuse and in 10 of those with a history of abuse. At the end of the biofeedback training, $56 / 60(93 \%)$ of the former and 10/10 (100\%) of the latter had a successful response, according to the criteria described above: this difference was not significant $(\mathrm{p}=$ 0.53 ) between the two groups. No differences between manometric or defecographic findings and between types of abuse were found concerning the response to biofeedback treatment.

\section{DISCUSSION}

In this study we report that the prevalence of sexual/physical or psychological abuse in patients referred to a general gastroenterology practice is slightly higher than $10 \%$, and lower than that reported by other authors $(14,15)$. However, the latter studies recruited patients referred to tertiary centers, more likely to be highly selected and having more associated pathologies. Of course, due to the peculiar, intimate, and difficult topic to face, which requires some deep and trusty relationship between patient and physician, there is the possibility that a history of abuse could have not been reported or elicited in some of the patients during their evaluation. Studies on patients with IBS, for instance, show different health seeking behaviors in patients with and without a history of abuse (22).

Biofeedback treatment is an effective option for patients with OD $(5,6,23)$, as was also recently demonstrated by controlled trials $(9,10,24)$, and the present study confirmed this. In fact, $94 \%$ of our patients undergoing this training had a successful response, al least in the short term; however, there is evidence of a sustained response of up to two years in up to $80 \%$ of patients (9). The efficacy of biofeedback training for OD is influenced by the skills of the biofeedback therapist and the technique used for training $(9,10)$. We feel that the good results we obtained were due to the treatment being administered by the same physician with a long-standing experience in such training, as shown in sexually abused women with anismus (25). Of course, different results may be obtained in different settings (26).

This study has limitations. We were unable to detect differences in the response to biofeedback treatment between patients with and without a history of abuse; this might be due to the small sample size of patients with such a history that underwent this treatment, even though it has been claimed that an abuse history has no relevant role in the pathogenesis of either functional or organic chronic gastrointestinal disorders, but it can affect their clinical expression irrespective of functional or organic diagnosis (27). Moreover, colonic transit was not evaluated; previous studies have shown reduced response rates to biofeedback training in patients with coexistent OD and slow transit compared to those with normal transit (28). This potential confounding factor was not assessed here. Finally, the period of observation of the results was limited to the treatment period; long-term data are needed to establish whether this treatment is effective in abused patients even in the long term, as demonstrated in patients with OD without a history of abuse (9).

However, we feel that these results might be of interest, since as far as we know there are no other such studies from South America evaluating the effect of biofeedback training in patients with OD and a history of abuse. Since there is literature evidence of strong and consistent relationships of sexual and physical abuse history with functional GI symptoms and disorders (29), further studies in larger cohorts of patients are needed to establish the proper effect of abuse on the effectiveness of biofeedback training in OD patients.

\section{REFERENCES}

1. Rao SS. Constipation: evaluation and treatment of colonic and anorectal motility disorders. Gastroenterol Clin North Am 2007; 36 : 687-711. 
2. Schmulson Wasserman M, Francisconi C, Olden K, Aguilar Paíz L, Bustos-Fernández L, Cohen $\mathrm{H}$, et al. The Latin-American consensus on chronic constipation. Gastroenterol Hepatol 2008; 31: 59-74.

3. Lembo A, Camilleri M. Chronic constipation. N Engl J Med 2003; 349: 1360-8.

4. Bassotti G, Whitehead WE. Biofeedback, relaxation training, and cognitive behaviour modification as treatments for lower functional gastrointestinal disorders. Q J Med 1997; 90: 545-50.

5. Bassotti G, Chistolini F, Sietchiping-Nzepa F, de Roberto G, Morelli A, Chiarioni G. Biofeedback for pelvic floor dysfunction in constipation. BMJ 2004; 328: 393-6.

6. Heymen S, Jones KR, Scarlett Y, Whitehead WE. Biofeedback treatment of constipation: a critical review. Dis Colon Rectum 2003; 46: 1208-17.

7. Iantorno G, Cinquetti M, Mazzocchi A, Morelli A, Bassotti G. Audit of constipation in a gastroenterology referral center. Dig Dis Sci 2007; 52: 317-20

8. D'Hoore A, Penninckx F. Obstructed defecation. Colorectal Dis 2003; 5: 280-7.

9. Chiarioni G, Whitehead WE, Pezza V, Morelli A, Bassotti G. Biofeedback is superior to laxatives for normal transit constipation due to pelvic floor dyssynergia. Gastroenterology 2006; 130: 657-64.

10. Rao SS, Seaton K, Miller M, Brown K, Nygaard I, Stumbo P, et al Randomized controlled trial of biofeedback, sham feedback, and standard therapy for dyssynergic defecation. Clin Gastroenterol Hepatol 2007; 5: 331-8.

11. Khalkin M, Wexner S. Treatment strategies in obstructed defecation and fecal incontinence. World J Gastroenterol 2006; 12: 3168-73.

12. Ali A, Toner BB, Stuckless N, Gallop R, Diamant NE, Gould MI, et al. Emotional abuse, self-blame, and self-silencing in women with irritable bowel syndrome. Psychosom Med 2000; 62: 76-82.

13. Ringel Y, Drossman DA, Leserman JL, Suyenobu BY, Wilber K, Lin W, Whitehead WE, et al. Effect of abuse history on pain reports and brain responses to aversive visceral stimulation: an FMRI study. Gastroenterology 2008; 134: 396-404.

14. Lopez Gaston AR, Andrüsch A, Catuogno P, Lopez de Luise G, Vazquez P. History of patients with pelvic floor dysfunction. Acta Gastroenterol Latinoam 2003; 33: 79-92.

15. Rao SS, Tuteja AK, Vellema T, Kempf J, Stessman M. Dyssynergic defecation: demographics, symptoms, stool patterns, and quality of life. J Clin Gastroenterol 2004; 38: 680-5.

16. Thompson WG, Longstreth GF, Drossman DA, Heaton KW, Irvine EJ, Muller-Lissner SA. Functional bowel disorders and functional abdominal pain. Gut 1999; 45: 43-7.

17. Bharucha AE, Wald A, Enck P, Rao S. Functional anorectal disor- ders. Gastroenterology 2006; 130: 1510-8.

18. Leserman J, Drossman DA, Li Z. The reliability and validity of a sexual and physical abuse history questionnaire in female patients with gastrointestinal disorders. Behav Med 1995; 21: 141-50.

19. Drossman DA, Leserman J, Nachman G, Li ZM, Gluck H, Toomey $\mathrm{TC}$, et al. Sexual and physical abuse in women with functional or organic gastrointestinal disorders. Ann Intern Med 1990; 113: 82833.

20. Leserman J, Drossman DA, Li Z, Toomey TC, Nachman G, Glogau L. Sexual and physical abuse history in gastroenterology practice: how types of abuse impact health status. Psychosom Med 1996; 58 : 4-15.

21. Schuster MM, Hookman P, Hendrix TR, Mendeloff A. Simultaneous manometric recording of internal and external anal sphincteric reflexes. Bull Johns Hopkins Hosp 1965; 116: 79-88.

22. Guthrie E, Creed F, Fernandes L, Ratcliffe J, Van Der Jagt J, Martin $\mathrm{J}$, et al. Cluster analysis of symptoms and health seeking behaviour differentiates subgroups of patients with severe irritable bowel syndrome. Gut 2003; 52: 1616-22.

23. Battaglia E, Serra AM, Buonafede G, Dughera L, Chistolini F, Morelli A, et al. Long-term study on the effects of visual biofeedback and muscle training as a therapeutic modality in pelvic floor dyssynergia and slow-transit constipation. Dis Colon Rectum 2004; 47: $90-5$.

24. Heymen S, Scarlett Y, Jones K, Ringel Y, Drossman D, Whitehead WE. Randomized, controlled trial shows biofeedback to be superior to alternative treatments for patients with pelvic floor dyssynergiatype constipation. Dis Colon Rectum 2007; 50: 428-41.

25. Leroi AM, Duval V, Roussignol C, Berkelmans I, Peninque P, Denis P. Biofeedback for anismus in 15 sexually abused women. Int J Colorectal Dis 1996; 11: 187-90.

26. Brusciano L, Limongelli P, del Genio G, Sansone S, Rossetti G, Maffettone $\mathrm{V}$, et al. Useful parameters helping proctologists to identify patients with defaecatory disorders that may be treated with pelvic floor rehabilitation. Tech Coloproctol 2007; 11: 45-50.

27. Baccini F, Pallotta N, Calabrese E, Pezzotti P, Corazziari E. Prevalence of sexual and physical abuse and its relationship with symptom manifestations in patients with chronic organic and functional gastrointestinal disorders. Dig Liver Dis 2003; 35: 256-61.

28. Chiarioni G, Salandini L, Whitehead WE. Biofeedback benefits only patients with outlet dysfunction, not patients with isolated slow transit constipation. Gastroenterology 2005; 129: 86-97.

29. Leserman J, Drossman DA. Relationship of abuse history to functional gastrointestinal disorders and symptoms: some possible mediating mechanisms. Trauma Violence Abuse 2007; 8: 331-43. 